\title{
SOBRE O PAPEL DA HISTÓRIA
}

\section{Maria de Lourdes Pinto de Almeida}

\section{Resumo}

Neste artigo, discute-se o papel da ciência da história. O conhecimento científico, desde a sua origem, tem se marcado por uma constante busca do rigor na compreensão da realidade. Ao demarcar seu espaço próprio, a ciência caracteriza-se sempre pela referência ao seu outro, a não ciência. A discussão em torno do estatuto da História exige algumas considerações em torno do regimento da ciência em geral. Contudo, uma análise do desenvolvimento da ciência nos mostra a sua historicidade, pois os seus critérios têm se transformado, sofrendo incrementos conforme as vicissitudes ou as marcas da temporalidade da interação humana.

\section{Palavras-chave}

Ciência-História ; Ciência-Pesquisa; Pesquisa histórica

In this paper is analyzed the role of History as a science. Since his origin the scientific knowledge is preoccupied with a search of a rigour. For to demarcate his own space science concerned always for no-scientific-field. The discussion about the History's epistemological statute demands some general considerations on science's regiment. However science is a historical phenomenon. His criterions have been changed in accordance with vicissitudes or the marks of human interaction temporality.

\author{
Abstract \\ Science-History; Science-Research; Historical research
}

\section{INTRODUÇÃO}


O conhecimento científico desde a sua origem tem se marcado por uma constante busca do rigor na compreensão da realidade. Tal rigor visa, sobretudo, um autocontrole fundado em critérios de validade que ao mesmo tempo objetiva dar a ciência parâmetros para sua avaliação, permitindo também demarcar o seu espaço enquanto tal. Nesse sentido, a ciência caracteriza-se sempre pela referência ao seu outro, a não ciência. A discussão em torno do estatuto da história exige algumas considerações gerais em torno do regimento da ciência em geral. Uma análise do desenvolvimento da ciência nos mostra a sua historicidade, pois os seus critérios têm se transformado sofrendo incrementos conforme as vicissitudes. A História em sua afirmação enquanto ciência também apresenta os efeitos da historicidade. A historicidade caracteriza-se enquanto determinações decorrentes da interação dos elementos que compõem a realidade humana numa determinada época.

$\mathrm{Na}$ configuração de uma época alguns elementos se preponderam. Nesse sentido, é que dizemos que as relações de produção, a materialidade dos elementos determinantes da vida dos homens, que os distribuem conforme os "lugares" ou espaços sociais de um dado modo de produção, engendram certas práticas sociais que devem ser compreendidas a partir do conjunto das determinações, quer dizer do concreto. Por mais determinista que semelhante terminologia possa ser interpretada, ela faz parte também de um ideário "humanista" calcado em determinados valores que têm apresentados como parâmetros para se julgar as ações caracterizadas como históricas e, ainda, para orientar planos de ação.

A ciência, sendo um produto da ação humana, marca-se por semelhante especificidade. Assim, alguns critérios têm surgido e desaparecido, outros prevalecem desde os projetos "epistemológicos" dos antigos gregos. Que os critérios, os valores, são humanos ninguém os nega. No entanto, deduzir que disso decorreria um total relativismo, ceticismo ou "anarquismo" (axiológico e epistemológico) seria radicalizar ao extremo o próprio principio da historicidade, que submete tudo às determinações temporais. Se os homens substituem seus critérios é por que o fazem em vista de um outro julgado melhor. O melhor já supõe um sentido que pode ser dado por vários critérios seja de utilidade, de "instrumentalidade", de operacionalidade, coerência lógica ou de conformidade com a experiência, etc. Essa possibilidade de criar, recriar ou aperfeiçoar critérios revela a atividade de um sujeito atuante, capaz de agir, conhecer e determinar parâmetros para suas preferências.

É em função do estabelecimento dos critérios para julgar suas práticas - para justificá-las, refutá-las ou transformá-las - é que se travam os embates ideológicos. Disputas fundadas $\mathrm{em}$ "última instância" na defesa de interesses econômicos, determinados pelas correlações contrárias e contraditórias de "forças" num determinado ordenamento de um modo de produção. Querer negar esse suposto eqüivale a aceitar como absolutas, as formas de organização social do momento. Como se o homem devesse 
renegar a sua capacidade de dar sentido, de "projetar", o que significa no vocabulário marxista o intento de buscar superar contradições nos mais diversos níveis da atividade humana (coletiva). Negar as contradições ou negar que elas possam ser superadas já supõe um compromisso com um lado, portanto um interesse de classe, uma vez que as relações entre o trabalho e a propriedade (no caso atual o capital), conforme um critério mais universal de compreensão da realidade humana, revela uma sociedade dilacerada pelo antagonismo de classe. Esse critério de compreensão da realidade humana pode muito bem ser aquele proposto por E. Kant: nunca tratar o homem como meio, mas sempre como fim em si mesmo.

Trata-se de um critério em torno do qual todo debate deve começar e deve se encerrar. No entanto, deve ir além de Kant no que se refere ao formalismo ou substancialismo da concepção de natureza humana. O homem é resultante de relações sociais no interior de um sistema cujas coordenadas são dadas pelos fatores econômicos. É, desse modo, como membro de uma sociedade, e não formalmente, que o homem deve ser visto como fim. Por isso todo plano de transformação da realidade humana possui uma dimensão coletiva, libertária. $\mathrm{O}$ eixo fundamental de definição de humanidade é a idéia de igualdade, não só formal e jurídica, mas, sobretudo, de condições de acessos aos benefícios conquistados pela humanidade. Tudo isso é impensável sem a discussão de novas formas de relação entre trabalho e proprieqade quer a nível intelectual ou material ${ }^{\text {. }}$

A definição de ciência como atividade humana exige que se compreenda esta, enquanto superestrutura, determinada por condições mais fundamentais, as econômicas. Sendo essas determinadas pela práxis social dos homens, que lutam pela manutenção dos interesses econômicos antagônicos que os dividem em opressores e oprimidos, dominantes e dominados (termos que os cientistas sociais de certas linhagens ideológicas negam-se a exprimir ou os exprimi com certa "vergonha" por sua suposta falta de rigor, isto é de objetividade e imparcialidade, no entanto basta olharmos ao redor para percebermos a pertinência significativa dos mesmos) move a história, até quando propõem o fim da mesma. A história resulta da ação dos homens que, conforme a idéia de práxis, atuam no "interior" de estruturas que são ao mesmo tempo determinantes e determinadas. Tal como a negação da filosofia exige o filosofar, a negação da História - como movimento dialético de produtor/produto, indivíduos/sociedade, infra-estrutura/super estrutura, e ciência/objeto-supõe compromissos

\footnotetext{
1 A crítica que Marx faz aos economistas do século XVIII dirige-se também aos filósofos. "Os profetas do século XVIII, sobre cujos ombros se apoiam inteiramente Smith e Ricardo, imaginam este indivíduo do século XVIII (...) um ideal, que teria existido no passado. Vêem-no não como resultado histórico, mas como ponto de partida da História, porque o conspiravam como um indivíduo conforme a natureza - dentro da representação que tinham de natureza humana que não se originou historicamente, mas foi posto como tal pela natureza. Esta ilusão tem sido partilhada por todas as novas épocas, até o presente “. In Para Crítica da economia política, Editora Nova cultural, p.03/04".
} 
históricos de classe. Os mesmos interesses ideológicos que explicariam a recusa do se pensar e buscar meios de superar a "transformação do homem" trabalhador ou despossuído dos meios de produção, do capital - em mercadoria no interior das relações capitalistas, poderiam ser associados aos escusos interesses daqueles que propõem ou aceitam a transformação da ciência em peça do mesmo gênero.

O grande problema para uma abordagem histórica refere-se ao perigo ou ao proveito para muitos de se cair no ecletismo. Seria, sem dúvida, a posição mais cômoda, uma vez que o melhor de cada escola ou doutrina sempre se evidencia, oferecendo-se facilmente para um pensamento "colecionador". Mas um quadro teórico impõe limites de coerência, cuja ultrapassagem representam rupturas consigo mesmo. Por outro lado, as verdades emergentes de uma concepção de ciência tornam-se totalmente descaracterizada num outro contexto. $\mathrm{O}$ eclético assemelhar-se-ia a um tecelão construtor de uma colcha de retalhos que jamais terminaria seu trabalho, pois sempre encontraria uma "novidade interessante" para juntá-la à sua coleção de pedaços de tecidos. Um correlato dessa posição, trajando as vestes de um anarquismo metodológico, seria o de supor que o método determina o objeto. Isso abre a porta para as mais diversas opções, uma vez que a polêmica em torno do objeto e de suas determinações e recortes está sempre presente entre os cientistas "sociais". A própria escolha do adjetivo para a determinação dos pesquisadores em questão já é uma problemática, uma vez que se poderia falar em ciência do homem, da cultura, da política, do espírito, etc, ou como se tem feito ultimamente "recortar" um objeto e contar sua história (como a história do sapato, do talher, etc.), abstraindo-se propositalmente ou não do contexto em que tudo se "configuraria", mais propriamente o concreto. Por outro lado aferrar-se dogmaticamente a uma doutrina, fazendo dela um "leito de Procusto" à qual tudo deva se submeter torna-se também uma atitude perigosa, ou seja, o esquecimento das determinações novas decorrentes das transformações e mesmo do progresso metodológico engendrado pela própria dinâmica do progresso científico. Cada escolha tem seu peso. O debate em torno da constituição da história enquanto disciplina científica mostra, muito bem, a amplidão dessa polêmica.

Disso resulta então a discussão do estudo da História quer como Ciêncja, como praxologia - prudência - ou arte.

Para que estudar a história? Há quem acredite que a história seria uma espécie de consciência coletiva, um saber a respeito de uma tradição enquanto meio

\footnotetext{
${ }^{2}$ Com relação à arte, compara-se a História no sentido de depreciá-la enquanto ciência. RAMA exprime bem essa situação, quando afirma que “ la historia- naturalmente avecindada com el Arte - está en óptimas condiciones para aprehender intuitivamente el mundo real. Los autores que vem el parentesco de la historia com el arte destacan entonces la distancia de la Historia com la ciencia natural o la ciencia simplemente, y obtienen argumentos de las escuelas intelectualistas, de las cuales Bergson es notorio maestro. Autores que no tienen una preocupacion historica directa realzan, sin embargo, la História como un ejemplo en sus formulaciones teóricas. In Teoria de la historia..Madrid.Editorial Tecnos.1974.
} 
no qual um povo vive. Assim deve-se conhecê-la para melhor preservá-la. O espírito do povo ganha vida ao ser concebido como atmosfera no interior da qual as individualidades - a psicologia do indivíduo germina e se nutre. Nesse ponto cruza-se o historicismo romântico alemão e o positivismo. Deve se ressaltar que a visão positivista da história concebe o passado como um dado, como fonte do jurídico e do administrativo, fundando na "História" uma tecnocracia administrativa, fazendo dela - a História - uma auxiliar da sociologia.

Nesse sentido, o positivo seria aquilo que se sedimentou historicamente. Há ainda os positivistas envergonhados ou não que copcebem a história enquanto experiência. ${ }^{3}$ Mas há quem propõe a inutilidade da história, como uma ciência supérflua, como pretendem alguns pensadores que se encontram entre os ditos pós-modernos. Por fim, há os que acreditam que o estudo da história é uma espécie de dever para com a espécie, pois é na história e pela história que o homem supera as condições de alienação e as contradições sociais.

O processo da constituição da História disciplina científica - deve ser compreendido no interior da práxis humana. Se este termo supõe já uma opção teórica e política, ele merece uma justificativa. A práxis pode ser compreendida como um "correlato" do trabalho alienado, no sentido de uma atividade consciente de seus condicionamentos, das opções que a norteiam, dos meios que a viabilizam. A história não se reduz a "prudência", a

\footnotetext{
${ }^{3}$ Ver RAMA, idem. Principalmente capítulo " $\mathrm{La}$ historia como experiencia”.
}

velha sabedoria prática de Aristóteles, que alguns historiadores ressuscitaram no nome pomposo de "praxologia", esta investigação mais prescritiva do que descritiva ou explicativa, que não visa

4 - "Os circuitos causais da ação não se revelam por inteiro à visão imediata; daí a necessidade de uma conceituação que, prestando-se a matéria ou não, se apresentará como uma série de conceitos coordenados numa tópica ou organizados num sistema hipotético-dedutivo. Consideremos, com efeito, essa prática que é o jogo de xadrez. Uma teoria dos xeques que permitiria deduzir para todos os casos a estratégia ótima é possível em hipótese, mas irrealizável: uma máquina eletrônica para ganhar todos os lances deveria ter as dimensões de uma nação ou de um continente. Também um jogador humano não pode prever distintamente as diferentes seqüências possíveis de um lance que vai jogar daqui a cinco ou seis lances; mais à frente é a confusão. Felizmente, os tratados do jogo de xadrez distinguem grandes ideais - tipos de estratégia e de situações; não permitem em absoluto deduzir e ganhar de forma segura, mas orienta-se e evitar grandes erros. No que podemos ver uma alegoria de toda a praxeologia: certamente, a contingência, a "necessidade material", o caráter "indefinido"das coisas humanas não são o mesmo que a complicação perfeitamente definida de uma combinatória, disciplina matemática onde os números mais que astronômicos são moeda corrente; mas toda alegoria claudica de uma praxeologia dedutiva, que a visão bastante curta do jogador vai de encontro ao "todo confuso" de Aristóteles e que o manual do jogo elabore uma conceituação que se apresenta como uma tópica.É a mesma coisa quanto ao tabuleiro de xadrez internacional; quer aí joguemos nós mesmos, quer nos façamos de sociólogos de quem joga ou de historiadores dos que já jogaram, tem-se tudo a ganhar se se dispuser de uma teoria ou pelo menos de uma tópica das relações internacionais de uma filosofia política; a análise conceptual permite "definir a especificidade dos subsistemas, fornecer uma lista das principais variáveis, sugerir determinadas hipóteses relativas ao funcionamento, facilitar a discriminação entre as teorias e as pseudoteorias. VEYNE. Paul. A história conceptual In Jacques Le GOFF e Pierre NORA, História novos problemas, ed. Francisco Alves, p. 72-73. 
uma verdade - portanto não reivindica a cientificidade, uma vez que se propõe munir dos saberes das demais ciências. Enquanto esse saber estratégico, instrumental, a praxologia "serve" a "todos", se bem que tem sido amplamente aproveitada mais nos "jogos" governamentais ou nas disputas entre empresários. Mas cabe sempre insistir porque nos "jogos" os perdedores são sempre os mesmos. A noção de práxis, a pesar de ter as mesmas origens que a praxologia, ao ser refundada pelo marxismo ganhou um estatuto totalmente novo, digamos, revolucionário. A práxis vincula-se com a idéia de dialética, no sentido que supõe as contradições enquanto fator transformador da realidade, motor da história. Ela revela-se, portanto, enquanto consciência das determinações, no caso a base econômica, e enquanto proposta de atuação sobre a mesma, em vista de superar os dilaceramentos, as contradições decorrentes das relações de classe - contraídas pelos homens. A práxis supõe uma síntese dialética enquanto forma de superação das contradições e, portanto, uma possibilidade de se conceber e agir sobre a totalidade social. A concepção de História que aqui propomos é a de uma ciência rigorosa, capaz descobrir "verdades" a respeito de seu objeto, a realidade humana, as "leis" de "mudança" e "continuidade" determinantes das relações sociais, bem como de explicar suas contradições e, sobretudo, de fornecer um "conhecimento objetivo", não no sentido de uma mera ideologia, para incrementar a práxis social, e não apenas, os sistemas de controle político, produtivo e mercadológico, nem muito menos no sentido de saber estratégico para negociar "perdas e ganhos".

\section{CONSIDERAÇÕES FINAIS}

A historia não é ideologia, pois não resume no saber de uma classe, para uma classe. Aqui voltamos na questão central da idéia de "emancipação" ou do compromisso com a "humanidade". Conhecer e agir conforme o interesse do gênero humano supõe um compromisso de superar a exploração, a desigualdade, enfim todas as formas de alienação, a menos que se queira identificar o interesse "universal humano" com os interesses dos "vencedores", dos expropriadores do trabalho alheio. $\mathrm{O}$ intelectual, no caso o historiador, deve ser compreendido como um funcionário da humanidade ${ }^{5}$. Mas numa humanidade

\footnotetext{
5 Mesmo o próprio Foucault, o eliminado do homem enquanto "sujeito" nas ciências sociais ainda continuou atuando enquanto intelectual sujeito da historia, ou seja, propulsor de uma política progressista, enquanto prática implicada com as possibilidades de transformação. "Foucault tinha o mesmo problema com o intelectual que agia como guardião dos valores humanistas. Foucault tinha uma concepção inteiramente nova da posição política do intelectual, afirma Deleuze . 'Entre Voltaires e Zola e Sartre , há um longo percurso que termina com Sartre: o intelectual que intervém em nome de valores superiores. Com Foucault, a posição política do pensador mudou radicalmente... Esta era muito mais funcional... Ele perguntou, 'o que dizer, o que pensar?'. Este papel “funcional” do intelectual pode parecer familiar no exemplo dos centros governamentais de pesquisa. $\mathrm{O}$ que era único - e que distingue Foucault tanto do modelo sartreano quanto do modelo do pesquisador do governo - era o tipo de pensamento em que le se enganou e o processo de reformas com que ele se comprometeu. Foucault investigou a produção histórica de experiências individuais experiências tais como doença mental, crime, sexualidade e dependência - porque ele pensava que tais histórias poderiam representar um papel tático nas lutas políticas, ele acreditava que a
} 
dilacerada, cabe a ele optar ou não pela parte que representa a universalidade do interesse do "gênero" humano. Antes de falar que o conhecimento é ideologia de classe, deve se concebê-lo enquanto práxis social, caso contrário teríamos que admitir a perspectiva positivista da neutralidade da ciência ou aquele tipo de intelectual "universal" ou consciente das ideologias e ao mesmo tempo isento de suas "contaminações". tarefa de executar as mudanças deveria incluir todas as partes interessadas, incluindo os indivíduos que as sofressem: pacientes mentais, prisioneiros, beneficiários da previdência social. - Keith GANDAL, Michel Foucault: trabalho e política, in Revista de história, n. 1, Verão, 1989.p.108/109.

\section{BIBLIOGRAFIA}
ANDERY. M. A, e outros. Para compreender a Ciência: uma perspectiva histórica. Rio de Janeiro : Espaço e Tempo ; São Paulo: EDUC,1988. 
CARDOSO, CIRO F. S. Uma introdução à história. São Paulo : Brasiliense, [s.d.]

DOSSE, F. A História em migalhas : dos annales a nova história. Campinas, UNICAMP.

GARDINER, P. Teorias da história. Lisboa: Fundação Calouste Gulbenkian, 1964.

GAMBOA, S. A. S. Epistemologia da pesquisa em educação : estruturas lógicas e tendências metodológicas. Campinas, SP. Tese (Doutoramento). Faculdade de Educação, UNICAMP.

HEGEL,G.W.F. Coleção os Pensadores. São Paulo : Abril Cultural, [s.d.]

KANT, I. Idéia de uma História Universal de um ponto de vista cosmopolita. In: GARDINER, P. Teorias da História. Lisboa: Fundação Calouste Gulbenkian, 1964.

LOMBARDI, J.C. Marxismo e História da Educação: algumas reflexões sobre a historiografia educacional brasileira recente.Campinas, UNICAMP, tese de doutoramento.

MARX, Karl., ENGEL, Friedrich. $\boldsymbol{A}$ ideologia alemã. 3.ed. Lisboa : Presença Brasil : Martins Fontes, 1980.

MARX, Karl. O Capital. 7.ed. São Paulo : DIFEL, 1982. Livro I.

RODRIGUES, J. H. Teorias da História do Brasil. São Paulo : Nacional, [s.d.]

SILVA, M.B.N. da (Org.) Teoria da História. São Paulo : Cultrix,[s.d.]
VICO, G. Princípios de uma ciência nova. São Paulo : Abril Cultural, 1979. (Os Pensadores).

VOLTAIRE,. Oeuvres complètes. Paris : Garnier Frères, Libraires-Editeurs, 1879.

ZAIDAN FILHO. Michel. A crise da razão histórica. Campinas : Papirus.1989. 


\footnotetext{
Maria de Lourdes $\boldsymbol{P}$. de Almeida

Pedagoga, Mestre e Doutoranda em História da Educação pela Faculdade de

Educação

Universidade Estadual de Campinas. Secretária do Grupo de Estudos e Pesquisas

"História, Sociedade e Educação no Brasil" HISTEDBR

e-mail: malupalmeida@uol.com.br
} 